\title{
The Pyramidal Lobe of the Thyroid
}

\author{
Gregorio Patrizi ${ }^{*}$, Giorgio Di Rocco ${ }^{1}$, Domenico Giannotti ${ }^{1}$, Maria Giulia Bernieri², \\ Felice Sperandeo1, Rina Orkabi ${ }^{1}$, Paolo Onori ${ }^{3}$, Eugenio Gaudio ${ }^{3}$, Adriano Redler ${ }^{1}$ \\ ${ }^{1}$ Department of Surgical Sciences, Faculty of Medicine and Dentistry, Sapienza University of Rome, Rome, Italy \\ ${ }^{2}$ Department of Radiology, Oncology and Pathology, Faculty of Medicine and Dentistry, Sapienza University of \\ Rome, Rome, Italy \\ ${ }^{3}$ Department of Anatomical, Histological, Forensic Medicine and Orthopedic Sciences, Faculty of Pharmacy and \\ Medicine, Sapienza University of Rome, Rome, Italy \\ Email: ${ }^{2}$ g patrizi@yahoo.com
}

Received 20 August 2014; revised 5 October 2014; accepted 21 October 2014

Copyright (C) 2014 by authors and Scientific Research Publishing Inc.

This work is licensed under the Creative Commons Attribution International License (CC BY). http://creativecommons.org/licenses/by/4.0/

(c) (i) Open Access

\begin{abstract}
Anatomy of the thyroid has been extensively studied but the presence of pyramidal lobe varies in percentages from $15 \%$ to $75 \%$ of cases according to different authors. We therefore investigated systematically this peculiar anatomical aspect. From January 2001 to December 2011, 1002 patients underwent total thyroidectomy in our Division of General Surgery. We analyzed the data collected on the latest $\mathbf{2 0 0}$ thyroidectomies: for all patients pyramidal lobe was measured at removal of the specimen then dimension of the pyramidal lobe after fixation was checked. We found the pyramidal lobe in all cases. In most cases, it was approximately $2 \mathrm{~cm}$ (range $1-8 \mathrm{~cm}$ on fresh specimen). At histology it was described in $72 \%$ of cases, after fixation size decreased by a third approximatively. This is the first systematic intraoperative study to verify the prevalence of the thyroid pyramidal lobe. In our experience, the pyramidal lobe is always present and the thyroglossal duct is identifiable.
\end{abstract}

\section{Keywords}

Thyroid, Pyramidal Lobe, Thyroidectomy, Surgical Anatomy, Thyroid Anatomy, Thyroid Surgery, Neck Anatomy, Neck Surgery

\section{Introduction}

Although the anatomy of the neck in general and of the thyroid in particular has been extensively studied, the presence of accessory thyroid tissue is not yet fully elucidated. For example, the presence of the pyramidal lobe,

\footnotetext{
"Corresponding author.
}

How to cite this paper: Patrizi, G., Di Rocco, G., Giannotti, D., Bernieri, M.G., Sperandeo, F., Orkabi, R., Onori, P., Gaudio, E. and Redler, A. (2014) The Pyramidal Lobe of the Thyroid. Health, 6, 2535-2540. 
vestigial thyroglossal duct, is given in percentages ranging from $15 \%$ to $75 \%$ of cases [1] [2], though it is a topic of great interest, considering the possibilities of recurrence of disease in that site after total thyroidectomy, in which the removal of thyroid tissue macroscopically is indispensable.

Our experience, based on more than one thousand total thyroidectomies, has led us to reflect on this peculiar anatomical aspect, as another possible reason for the absence of recurrences of thyroid cancer in our casuistic over a ten-year period. All our patients operated for thyroid cancer were contacted and re-evaluated or interviewed by telephone and we found no case of recurrence to be treated surgically, except the case of a patient operated in another center to perform a lateral and central lymphadenectomy.

Aim of this paper is to propose our anatomical considerations on the pyramidal lobe, rather than analyzing the outcomes in thyroid surgery.

\section{Material and Methods}

From January 2001 to December 2011, 1002 patients underwent total thyroidectomy in our Division of General Surgery (Sapienza University of Rome, Department of Surgical Science, Division of General Surgery "G”, Chief: Prof. Adriano Redler). All patients were operated by the same surgeon and all histological specimen were analyzed by the same pathologist. All patients signed full informed consent. The surgical technique was the same for all patients [3]. 864 patients underwent total thyroidectomy for benign diseases and 138 for malignant pathologies (Table 1, Table 2). Mean age was 57 years for men and 50 years for women affected by benign disease and 56 in both sex for those who were affected by malignant disease (Table 3).

We analyzed particularly the data collected on the latest 200 thyroidectomies performed in our Division of General Surgery as follows:

- In all surgical procedures, two medical students attended in the operating room to register if the pyramidal lobe was present and to measure it each one independently as soon as the surgical specimen was removed. The measures started from the isthmus and extended up to the resection margin (Figure 1), excluding the fibrous part eventually present which is already a component of the thyroglossal duct. In addition, they recorded also if the origin of the pyramidal lobe was right- or left-sided.

- Afterwards, they were in charge to check the dimension of the pyramidal lobe after fixation in the macroscopic description of the gland in histology reports.

- All measures were recorded and compared.

\section{Results}

During surgery, we found the pyramidal lobe in all cases (Figure 2). Resection was performed en bloc and extended up to the insertion of the pyramid into the thyroglossal duct.

\begin{tabular}{ccc}
\multicolumn{3}{l}{ Table 1. Characteristics of the studied population (age and gender). } \\
\hline Age & Benign disease & Malignant disease \\
\hline Male & $57.5(26-89)$ & $57.2(28-82)$ \\
Female & $49.5(11-88)$ & $56(21-91)$ \\
Male:female ratio & $1: 3$ & $1: 2$ \\
\hline
\end{tabular}

Table 2. Characteristics of the studied population (benign diseases).

\begin{tabular}{cc}
\hline Benign disease & Number of patients \\
\hline Goiter & $724(83.8)$ \\
Basedow-graves-flajani & $91(10.6)$ \\
Plummer adenoma & $39(4.5)$ \\
Thyroiditis & $7(0.8)$ \\
Total & $\mathbf{8 6 4}$ \\
\hline
\end{tabular}


Table 3. Characteristics of the studied population (malignant diseases).

\begin{tabular}{cc}
\hline Malignant disease & Number of patients (\%) \\
\hline Papillary cancer & $115(83.9)$ \\
Follicular cancer & $9(6.6)$ \\
Medullary cancer & $5(3.6)$ \\
Anaplastic carcinoma & $4(2.7)$ \\
Hurthle cell carcinoma & $2(1.5)$ \\
Squamous carcinoma & $1(0.73)$ \\
Metastatic melanoma & $1(0.73)$ \\
Lymphoma & $1(0.73)$ \\
Total & $\mathbf{1 3 8}$ \\
\hline
\end{tabular}

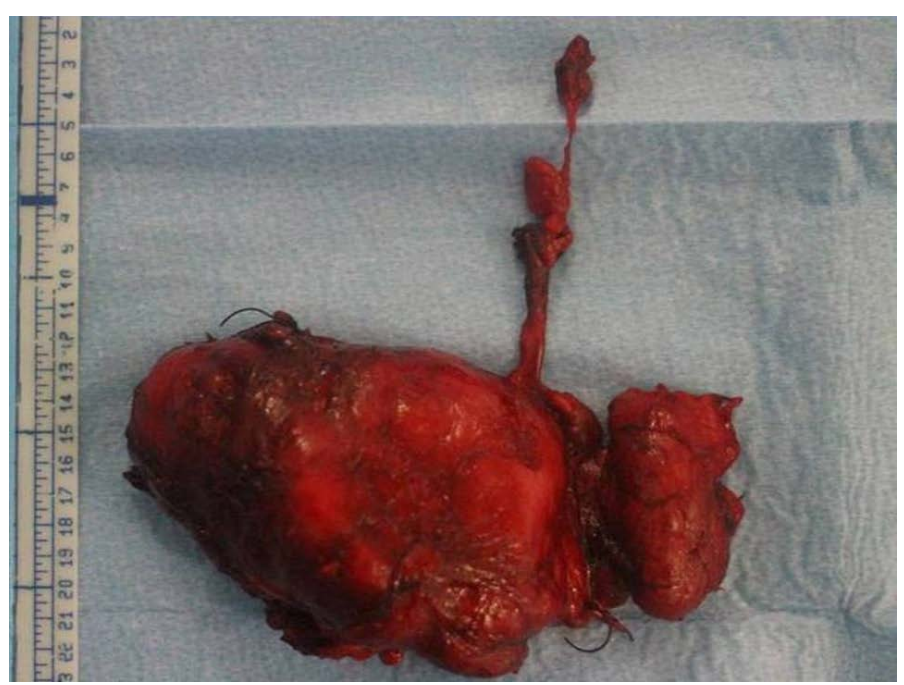

Figure 1. Operative specimen of a thyroid with its pyramidal lobe.

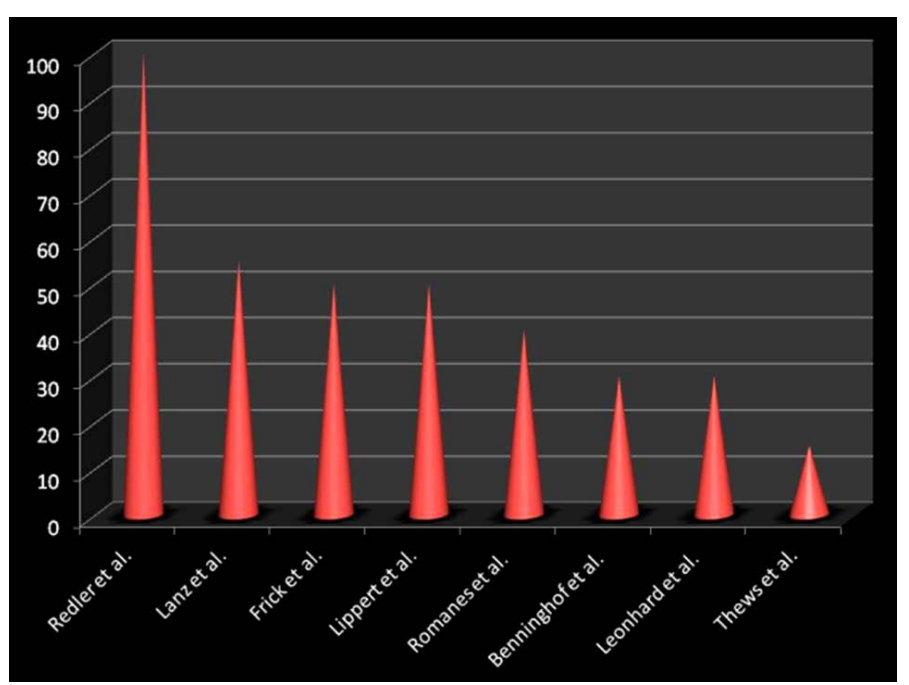

Figure 2. Frequency of identification of the pyramidal lobe according to different authors. 
In more than $50 \%$ of cases, the pyramidal lobe was approximately $2 \mathrm{~cm}$ in length, ranging from 1 to $8 \mathrm{~cm}$ on fresh specimen (Table 4). The measures recorded by the two students were fully concordant. At histology, the pyramidal lobe was described only in $72 \%$ of cases.

In $68 \%$ of cases, the pyramidal lobe arised from the left lobe of the gland.

After fixation, comparing our measurements with the dimensions reported by pathologists, size decreased by a third approximatively.

\section{Discussion}

From an embryological point of view, thyroid tissue appears on the $24^{\text {th }}$ day at the limit between the first and second brachial arch [4]. It appears initially as a thickening of the endodermic plaque at the floor of the pharyngeal rudiment and constitutes progressively a sac or thyroid diverticulum; initially loose, the diverticulum hardens progressively while the thyroid gradually migrates through the neck to reach its final position. During this passage, the thyroid remains closely adherent to the tongue through the thyroglossal duct. By the end of the seventh week of pregnancy, the thyroid has reached its position and adopted its adult form, losing its connection with the tongue, through duct degeneration, starting generally from its middle third, although the origin of thyroid primodium persists in the form of the foramen caecum of the tongue.

During its descent, a portion of the thyroid tissue may persist along the axis of the thyroglossal duct or even continue the descent to the bottom. These residues are the basis of several thyroid abnormalities such as ectopic thyroid, lingual thyroid, cysts or fistulae of thyroglossal duct. The pyramidal lobe is the lower portion of the thyroglossal duct and can be adherent to the hyoid bone by fibrous or muscular cords [5]-[7].

A more recent theory, formulated by Otto in 1994, calls into question the thyroid descent, in favor of a source next to the primordial heart while a second epithelial cord, the thyroglossal duct, would connect the thyroid to the tongue. That way you would have two different types of tissue, one arising from the oral cavity, the other from the thyroid itself. During the sixth week, the two epithelia would face regressive phenomena. Any alteration of this process would lead to anatomical abnormalities that contain thyroid tissue (ectopic thyroid, including the pyramidal lobe) or only epithelial tissue of the oral cavity (median cysts) [8].

From an anatomical point of view, alterations of downward migration of the thyroid gland or thyroglossal duct regression would result in thyroid abnormalities or morphological variations of the gland itself, pyramidal lobe, lingual thyroid, median cyst or additional thyroids [9]-[11].

The pyramidal lobe presents an extreme morphological variability (pyramidal form, cord forms, nodular forms or inverted $\mathrm{Y}$ ).

In literature all kinds of information about thyroid abnormalities can be found: in Anatomical texts, the pyramidal lobe rate stands between $15 \%$ and $75 \%$ (Thews [2]: at least 15\%; Leonhard [11]: 30\%; Benninghoff [12]: 30\%; Romanes [13]: 40\%; Lippert [14]: 50\%; Frick [10]: 50\%; Lanz [9]: >50\%).

Marshall was one of the first to describe anatomical changes of the thyroid, finding the pyramidal lobe in $43 \%$ of cases [15]; Blumberg [16] in 60\% - 65\%, usually located to the left of the midline.

In two different studies, Bergmann studied the incidence of pyramidal lobe and he found it initially in $68 \%$ of cases, and later in $40 \%$. The lobes were usually connected to isthmus on the left side and in about half of the cases, the pyramidal lobe was made of glandular tissue up to the hyoid bone which was fused or connected by fibrous or muscle tissue [17]. Tandler [18] described the pyramidal lobe as emerging from the gland at the conjunction of a lobe with isthmus, asymmetrically running until it reaches, often, the hyoid bone.

Sobotta made a review of the literature on the frequency of the pyramidal lobe, concluding, in line with Luschka, that it was present in one-third of the population, while Streckeisen and Testut identified in $75 \%$ of thyroids, Oseki in $71.7 \%$ and Zuckerkandl in $60 \%-70 \%$. Techini and Cavatorti noted that the presence of the pyramidal lobe was more frequent in men than women and in younger rather than elderly patients. In addition, a geographical variability was suggested.

Table 4. Average length of the pyramidal lobe according to gender.

\begin{tabular}{cc}
\hline Pyramidal lobe & Average length in cm (range) \\
\hline Male & $2.3(1-8)$ \\
Female & $1.9(1-6)$ \\
\hline
\end{tabular}


Skandalakis [19] refers to an absence of the isthmus in $10 \%$ of cases and a lobe in $1.7 \%$, while the pyramidal lobe would be present in $50 \%$ of the observations, like Bhatnagar [20], but each thyroid would be connected to foramen cecum by a fibrous cord.

More recently, some authors identified the pyramidal lobe in 55\% of thyroids, through analysis of the autopsy findings, operations and scintigraphy, more in men than in women, as also reported by Spencer on scintigraphy studies [21]. It is also evident how the pyramidal lobe is usually localized to the left and extends generally to the hyoid bone, with or without interposition of fibrous tissue, in line with what has already been noted by Bergmann and Blumberg [16] [17].

From a clinical point of view, morphological abnormalities can lead to problems during surgery. One of the reasons of recurrence can be precisely linked to the presence of an unidentified pyramidal lobe, superior additional thyroids, extension behind the trachea, under or to the side of the thyroid itself [22] [23].

However, few data in the literature regarding the extension or the length of the pyramidal lobe are available. In our experience, the lobe is about $2 \mathrm{~cm}$ in almost half of the cases and generally, when the lobe is longer it is also much thinner, as if it were stretched. If dissection is not perfectly careful and accurate, remnants of glandular tissue can be demonstrated by ultrasonography, elastosonography or scintigraphy affecting the accuracy of any preoperative diagnostic tool [24]-[28]. The completeness of the thyroidectomy, cornerstone of the treatment of surgical thyroid diseases in our School, may be jeopardized by the presence of an unidentified pyramidal lobe. The problem is also overwhelmingly in cases of thyroid cancer since that residue may invalidate the eventual radiometabolic therapy. Although the thyroid cells of the pyramidal lobe are usually functionally inactive as documented by years of scintigraphic studies, they can re-enable following the removal of the gland. And it is for the same reason that thyroglossal duct should be followed and resected up to its origin at the oral floor. We think that the cells of this structure, because of their common embryological origin with the thyroid, in the absence of the gland, can acquire metabolic and differentiation function.

The different results reported in literature are the consequence of "sampling": casuistic are frequently small and do not correlate the intraoperative observation with the histological examination leading to biases of fixation shrinkage [28]. Furthermore, depending on the surgical technique, blood can reflow from the thyroid, leading to an important volumetric decrease. Those aspects are a probable explanation for the variation of incidence of the pyramidal lobe in the different casuistics.

\section{Conclusion}

As far as we could observe, this is the first systematic study related to surgical practice to define the actual prevalence of the pyramidal lobe of the thyroid, about 250 years after Morgagni described it for the first time. In our experience, the pyramidal lobe is always present and the thyroglossal duct can be identified. For this reason, the surgical technique we adopt is a total thyroidectomy, pursuing the "protrusions" of the thyroid to the limit of their extention, regardless of their precise localization.

\section{References}

[1] Sobotta, J. (1915) KV Bardeleben’s Handbuch der Anatomie des Menschen, Band III, 3. Abteilung, 4. Teil, Anatomie der Schilddrüse. Fischer, Jena, 165-183.

[2] Thews, G., Mutschler, E. and Vompel, P. (1999) Anatomie Physiologie Pathophysiologie des Menschen. Wissenschaftliche VerlagsgesellschaftmbH, Stuttgart, 491-496.

[3] Cirocchi, R., Trastulli, S., Sanguinetti, A., Cattorini, L., Covarelli, P., Giannotti, D., Di Rocco, G., Rondelli, F., Barberini, F., Boselli, C., Santoro, A., Gullà, N., Redler, A. and Avenia, N. (2011) Recurrent Differentiated Thyroid Cancer: To Cut or Burn. World Journal of Surgical Oncology, 9, 89. http://dx.doi.org/10.1186/1477-7819-9-89

[4] Braun, E.M., Windisch, G., Wolf, G., Hausleitner, L. and Anderhuber, F. (2007) The Pyramidal Lobe: Clinical Anatomy and Its Importance in Thyroid Surgery. Surgical and Radiologic Anatomy, 29, 21-27. http://dx.doi.org/10.1007/s00276-006-0165-1

[5] Moore, K.L. and Persaud, T.V.N. (1993) The Developing Human. Clinically Oriented Embryology. WB Saunders Company, Philadelphia, 200-203.

[6] O’Rahilly, R. and Müller, F. (1992) Human Embryology and Teratologie. Wiley-Liss, New York, 227-230.

[7] Starck, D. (1965) Embryologie. Ein Lehrbuch auf allgemeinbiologischer Grundlage. Thieme, Stuttgart, 456-458.

[8] Otto, H.D. (1994) Teratogenetische und klinische Aspektebei Mißbildungen des Kopf- und Halsbereiches. European 
Archives of Oto-Rhino-Laryngology. Supplement, 1, 15-100.

[9] Lanz, T. and Wachsmuth, W. (1955) Praktische Anatomie. Band 1, Teil 2. Hals. Springer, Berlin, 214-264.

[10] Frick, H., Leonhardt, H. and Starck, D. (1987) (Allgemeine Anatomie. Spezielle Anatomie I Extremitäten-Rumpfwand-Kopf-Hals. Thieme, Stuttgart, New York, 778-780.

[11] Leonhardt, H., Tillmann, B., Töndury, G., et al. (1987) Band Innere Organe. In: Rauber/Kopsch, Eds., Anatomie des Menschen, Thieme, Stuttgart, 214-220.

[12] Benninghoff, A. and Drenckhahn, D. (2004) Anatomie, Makroskopische Anatomie, Histologie, Embryologie, Zellbiologie. Band 2. Urban \& Fischer, München, 197-203.

[13] Romanes, G.J. (1981) Cunningham’s Textbook of Anatomy. Oxford University Press, Oxford, 595-598.

[14] Lippert, H. (2000) Lehrbuch Anatomie. Urban \& Fischer, München, Jena, 585-589.

[15] Marshall, C.F. (1895) Variations in the Form of the Thyroid Gland in Man. Journal of Anatomy and Physiology, 29, 234-239.

[16] Blumberg, N.A. (1981) Observation on the Pyramidal Lobe of the Thyroid Gland. South African Medical Journal, 59, 949-950.

[17] Bergmann, R.A., Thompson, S.A. and Afifi, A.K. (1988) Compendium of Human Anatomic Variations. Urban \& Schwarzenberg, Baltimore, Munich, 175.

[18] Tandler, J. (1923) Lehrbuch der systematischen Anatomie. Band 2. Die Eingeweide. Verlag von F. C. W. Vogel, Leipzig, 78-83.

[19] Skandalakis, J.E., Gray, S.W. and Rowe Jr., J.S. (1989) Anatomischbedingte Komplikationen in der Allgemeinchirurgie. Thieme, Stuttgart, 10-18.

[20] Bhatnagar, K., Nettleton, G.S. and Wagner, C. (1997) Subisthmic Accessory Thyroid Gland in Man: A Case Report and a Review of Thyroid Anomalies. Clinical Anatomy, 10, 341-344. http://dx.doi.org/10.1002/(SICI)1098-2353(1997)10:5<341::AID-CA10>3.0.CO;2-K

[21] Spencer, R.P., Scholl, R.J. and Erbay, N. (1997) Tc-99m Pertechnetate Thyroid Images in Hyperthyroidism: Size, Distribution and Presence of a Pyramidal Lobe. Clinical Nuclear Medicine, 22, 519-522. http://dx.doi.org/10.1097/00003072-199708000-00001

[22] Else, J.E. (1930) Anatomical Variations in the Thyroid as a Cause of Recurrent Goiter. American Journal of Surgery, 8 , 92-96. http://dx.doi.org/10.1016/S0002-9610(30)90894-X

[23] Hollinshead, W.H. (1961) Anatomy for Surgeons, Vol. 2. The Head and the Neck. Hoeber-Harper, New York, 517531.

[24] Cantisani, V., D’Andrea, V., Biancari, F., Medvedyeva, O., Di Segni, M., Olive, M., Patrizi, G., Redler, A., De Antoni, E.E., Masciangelo, R., Frezzotti, F. and Ricci, P. (2012) Prospective Evaluation of Multiparametric Ultrasound and Quantitative Elastosonography in the Differential Diagnosis of Benign and Malignant Thyroid Nodules: Preliminary Experience. European Journal of Radiology, 81, 2678-2683. http://dx.doi.org/10.1016/j.ejrad.2011.11.056

[25] Cantisani, V., D’Andrea, V., Mancuso, E., Maggini, E., Di Segni, M., Olive, M., Lodise, P., Palermo, S., De Antoni, S., Redler, A., Patrizi, G., Porfiri, A., Panzironi, G. and Ricci, P. (2013) Prospective Evaluation in 123 Patients of Strain Ratio as Provided by Quantitative Elastosonography and Multiparametric Ultrasound Evaluation (Ultrasound Score) for the Characterisation of Thyroid Nodules. La Radiologia Medica, 118, 1011-1021. http://dx.doi.org/10.1007/s11547-013-0950-y

[26] Vendettuoli, D., Di Rocco, G., Patrizi, G., Giannotti, D., Santoro, A. and Redler, A. (2010) Association between Thyroiditis and Cancer. Our Experience. Il Giornale di Chirurgia, 31, 286-288.

[27] Fiengo, L., Patrizi, G., Cancrini, G., Cinconze, F., Solai, F. and Arcieri, S. (2007) Thyreopathy Associated with Vagus Schwannoma. Annali Italiani di Chirurgia, 78, 73-75.

[28] Chen, C.H., Hsu, M.Y., Jiang, R.S., Wu, S.H., Chen, F.J. and Liu, S.A. (2012) Shrinkage of Head and Neck Cancer Specimens after Formalin Fixation. Journal of the Chinese Medical Association, 75, 109-113. http://dx.doi.org/10.1016/j.jcma.2012.02.006 
Scientific Research Publishing (SCIRP) is one of the largest Open Access journal publishers. It is currently publishing more than 200 open access, online, peer-reviewed journals covering a wide range of academic disciplines. SCIRP serves the worldwide academic communities and contributes to the progress and application of science with its publication.

Other selected journals from SCIRP are listed as below. Submit your manuscript to us via either submit@scirp.org or Online Submission Portal.
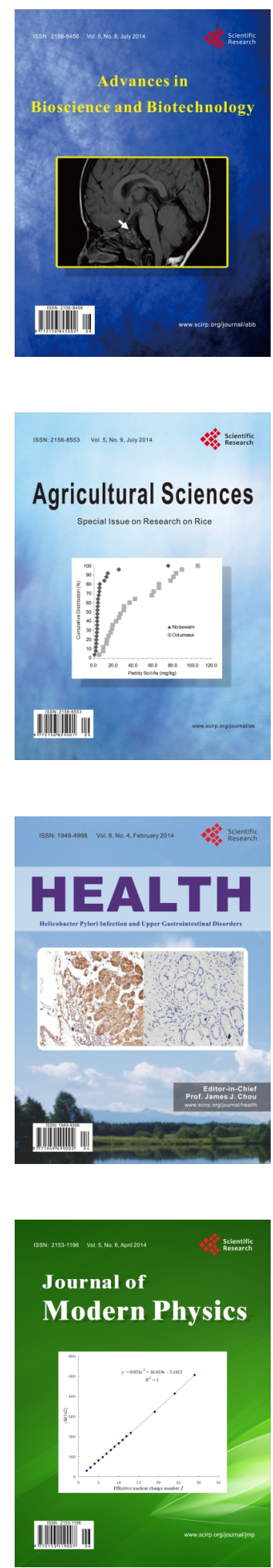
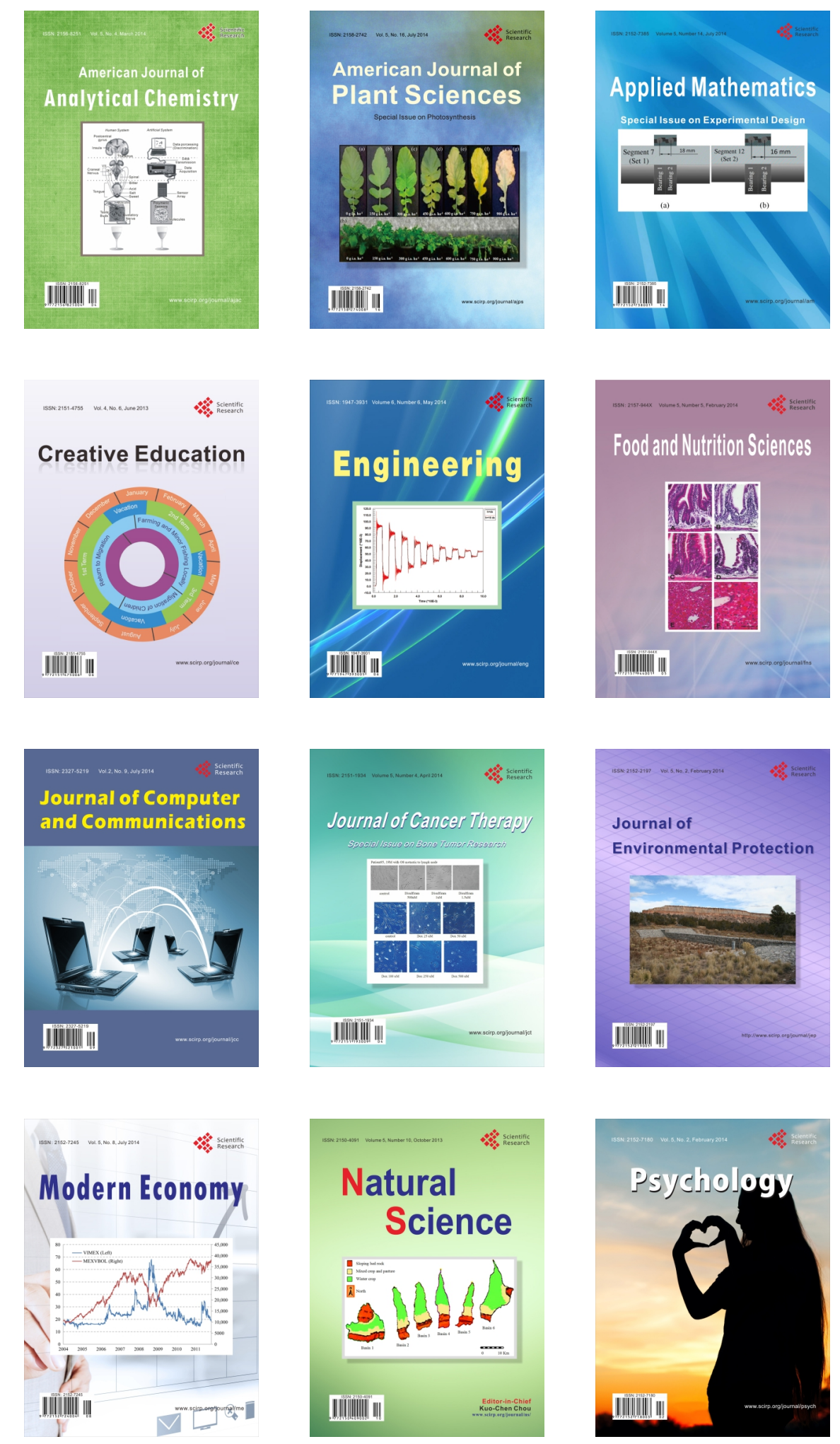